\title{
Perencanaan Karier Siswa: Kajian Berdasarkan Program Studi Keahlian di SMK
}

\author{
${ }^{1}$ Isna Tania, ${ }^{2}$ Daharnis, ${ }^{3}$ Afrizal Sano \\ ${ }^{1}$ Bimbingan dan Konseling, Universitas Negeri Padang, \\ 2 Bimbingan dan Konseling, Universitas Negeri Padang, \\ ${ }^{3}$ Bimbingan dan Konseling, Universitas Negeri Padang \\ Correspondence:email. ${ }^{1}$ isnatania92@gmail.com
}

\begin{abstract}
Abstrak: Di Sekolah Menengah Kejuruan ada siswa yang belum mencapai perkembangan karier yang optimal. Penelitian ini bertujuan untuk mendeskripsikan persepsi siswa tentang program studi keahlian yang ditempati dan perencanaan karier siswa serta menguji hubungan antara persepsi siswa tentang program studi keahlian yang ditempati dengan perencanaan karier. Penelitian ini adalah penelitian korelasional, dengan sampel 260 siswa yang dipilih dengan teknik Proportional Random Sampling. Instrumen yang digunakan adalah skala model likert. Analisis deskriptif dilakukan dengan menentukan nilai skor dan persentase. Pengujian hipotesis penelitian menggunakan rumus korelasi Pearson Product Moment. Temuan penelitian menunjukkan: (1) persepsi siswa tentang program studi keahlian yang ditempati berada pada kategori positif, (2) perencanaan karier siswa berada pada kategori baik, (3) terdapat hubungan yang signifikan antara persepsi siswa tentang program studi keahlian yang ditempati dengan perencanaan karier, dengan koefisien korelasi 0,801 pada taraf signifikansi 0,000 . Penelitian ini merekomendasikan perlunya peningkatan perencanaan karier siswa yang dapat dilakukan antara lain dengan mengubah persepsi siswa tentang program studi keahlian yang ditempatinya.
\end{abstract}

Kata kunci: Program Studi Keahlian, Perencanaan Karier

Abstract: In the vocational schools there were students who didn't achieved optimal career development. The purpose of this research is to describe student's perception about the expertise study programs, career planning and examine the relationship between both of variables. This correlation research was used 120 students as sample and selected by Proportional Random Sampling technique. Instrument was used Likert model scale. Descriptive analyze was done by determined value and percentage score. Pearson Product Moment formula was used for hypothesis testing. The result show that: (1) the student's perception about expertise study programs was positive (2) student's career planning was good (2) there was significant relationship between student's perception with career planning, with coefficient 0.801 and significance level at 0.000 . Research result recommend that improvement of career planning can be done by change student's perception about the expertise study programs.

Keyword: Expertise Study Programs, Career Planning 


\section{PENDAHULUAN}

Perkembangan karier pada masa remaja ditunjukkan oleh kecenderungan minat dan pilihan karier (Makmun, 2012) dalam mengembangkan potensi dan mempersiapkan diri untuk memasuki karier (Supriatna \& Budiman, 2010). Salah satu tugas perkembangan remaja, yaitu merencanakan karier. Remaja yang merencanakan karier berupaya mengolah informasi tentang diri dan lingkungan untuk menentukan tujuan yang hendak dicapai (Winkel \& Hastuti, 2013).

Hal yang telah terjadi pada remaja yang berada pada jenjang pendidikan Sekolah Menengah Kejuruan (SMK) dalam menjalani tugas perkembangan karier, yaitu merasa ragu terhadap program studi keahlian yang ditempatinya sehingga aktivitas yang dilakukan kurang mengarah pada perencanaan karier yang matang. Berdasarkan hasil penelitian, hambatan siswa dalam menentukan pilihan karier, yaitu teman-teman memberikan masukan yang berbeda dengan pilihan kariernya, kurang begitu yakin dengan keadaan fisik saat ini bisa mendapatkan pekerjaan yang sesuai dengan keinginan, hasil belajar kurang menunjang untuk pilihan karier nantinya dan banyaknya kebutuhan anggota keluarga membuat pesimis untuk melanjutkan studi (Falentini, Taufik, \& Mudjiran, 2013).

Hambatan yang dialami oleh siswa tersebut menunjukan gejala perencanaan karier yang masih kurang terarah. Siswa yang kurang dapat merencanakan karier secara terarah akan mengalami kesulitan dalam mencapai tugas perkembangan karier yang optimal. Individu yang gagal mempersonalisasi pengetahuan dunia kerja ke dalam situasi spesifik sering mengalami kesulitan dalam membuat keputusan sehingga memiliki aspirasi yang tidak realistis dan tujuan yang di luar kemampuan (Gladding, 2012).

Gejala yang terjadi menunjukkan perlunya pelayanan Bimbingan dan Konseling yang akurat bagi siswa SMK dalam bidang pengembangkan karier. Pelayanan Bimbingan dan Konseling yang luas dan efektif berguna untuk membantu siswa mencapai tugas perkembangannya dan mengatasi permasalahan yang dialami dalam rangka mengenal diri, mengenal lingkungan dan merencanakan masa depan (Prayitno \& Amti, 2004).

Permasalahan yang terjadi disebabkan oleh banyaknya faktor yang mempengaruhi perkembangan karier siswa. Salah satu faktor yang terkait dengan perencanaan karier adalah persepsi tentang lingkungan. Myers Briggs mengemukakan, In dealing with the world, the first step is perception. People form perceptions of events, people, objects and ideas as they become aware of the information. Then the individual must decide or make conclusions about the observed events, people, objects or ideas (Sharf, 2010). Pendapat tersebut menjelaskan individu menentukan karier berdasarkan persepsi yang dimiliki tentang lingkungan yang diamatinya.

William James menyatakan persepsi terbentuk atas dasar data-data yang diperoleh dari lingkungan yang diserap oleh indra dan diolah kembali berdasarkan pengalaman yang dimiliki (Sumanto, 2014). Persepsi juga merupakan proses mengatur dan mengartikan informasi sensori untuk memberikan makna (King, 2012). Berdasarkan pendapat para ahli tersebut data-data atau keterangan tentang karakteristik program studi keahlian akan membentuk persepsi siswa tentang program studi keahlian yang dibidangi. Persepsi yang kurang tepat tentang program studi keahlian akan mengurangi ketertarikan siswa untuk melaksanakan aktivitas yang berkaitan dengan program studi keahlian dan perencanaan karier. Jika hal ini terjadi pada siswa SMK maka dapat menghambat siswa dalam merencanakan karier yang matang.

Berdasarkan hasil wawancara peneliti, ditemukan siswa memasuki SMK karena dorongan dari orangtua, tidak diterima di SMA dan atas keinginan sendiri, namun tidak menempati program studi keahlian yang diinginkan. Selain itu, ada siswa yang menyatakan belum menentukan setelah tamat sekolah akan bekerja atau kuliah dan hanya sebagian kecil siswa yang mengkonsultasikan tentang karier dengan guru BK. Ada siswa yang akan melanjutkan ke perguruan tinggi, tetapi memilih program studi keahlian yang berbeda dengan program studi keahlian yang sedang ditempatinya sekarang. Hal yang dilakukan siswa dalam mengembangkan kemampuannya terkait dengan program studi keahlian yang ditempati, yaitu hanya mengikuti seminar dan uji kompetensi.

Berdasarkan fenomena yang ditemukan peneliti tertarik mengkaji tentang perencanaan karier siswa SMK berdasarkan persepsi tentang program studi keahlian yang ditempati. 


\section{METODE}

Penelitian yang dilakukan menggunakan metode kuantitatif dengan pendekatan deskriptif dan korelasional. Penelitian ini menggunakan sampel sebanyak 260 siswa yang diperoleh dengan teknik Propotional Random Sampling. Instrumen yang digunakan adalah skala model Likert. Data yang diperoleh dianalisis dengan menggunakan statistik deskriptif dan untuk menguji hubungan antara persepsi siswa tentang program studi keahlian dengan perencanaan karier digunakan rumus korelasi Pearson Product Moment dengan bantuan program SPSS for windows release 20 .

Tabel 1. Distribusi Sampel Penelitian

\begin{tabular}{clcc}
\hline \multirow{2}{*}{ No } & \multirow{2}{*}{ Program studi keahlian } & \multicolumn{2}{c}{ Jumlah } \\
\cline { 3 - 4 } & & X & XI \\
\hline 1. & Akomodasi Perhotelan & 23 & 19 \\
2. & Jasa Boga & 23 & 33 \\
3. & Tata Busana & 34 & 42 \\
4. & Tata Kecantikan Rambut & 11 & 10 \\
5. & Tata Kecantikan Kulit & 12 & 10 \\
6. & Teknik Komputer & 11 & 10 \\
7. & Jaringan & & \\
8. & Patiseri Perjalanan Wisata & 11 & - \\
\hline \multicolumn{2}{c}{ Total } & \multicolumn{2}{c}{$\mathbf{2 6 0}$ orang } \\
\hline
\end{tabular}

\section{HASIL DAN PEMBAHASAN}

Persepsi siswa tentang program studi keahlian yang ditempati dapat dilihat dari aspek, yaitu persepsi siswa tentang pembelajaran, persepsi siswa tentang kesesuaian program studi keahlian dengan dirinya dan persepsi siswa tentang prospek program studi keahlian.

Gambaran persepsi siswa tentang program studi keahlian berdasarkan hasil pengolahan data dijabarkan pada Tabel 2.

Tabel 2. Persepsi Siswa tentang Program Studi Keahlian

\begin{tabular}{lccc}
\hline \multirow{2}{*}{ Sub Variabel } & \multicolumn{2}{c}{ Rata-rata } & \multirow{2}{*}{ Kategori } \\
\cline { 2 - 3 } & Skor & \% & \\
\hline Pembelajaran & 3,96 & 79,13 & Positif \\
Kesesuaian Program & 3,68 & 73,63 & Positif \\
$\begin{array}{l}\text { Studi Keahlian } \\
\text { Prospek Program } \\
\text { Studi Keahlian }\end{array}$ & 3,92 & 78,46 & Positif \\
\hline \multicolumn{1}{c}{ Keseluruhan } & 3,86 & 77,34 & Positif \\
\hline
\end{tabular}

Data pada Tabel 2 menunjukkan secara keseluruhan skor rata-rata persepsi siswa tentang program studi keahlian yang ditempati sebesar 3,86 (77,34\%) dan berada pada kategori positif. Artinya, secara umum siswa memiliki penilaian dan penafsiran yang positif tentang program studi keahlian yang ditempatinya.

Selanjutnya, gambaran perencanaan karier siswa berdasarkan hasil pengolahan data dijabarkan pada Tabel 3.

Tabel 3. Perencanaan Karier Siswa

\begin{tabular}{lccc}
\hline \multirow{2}{*}{ Sub Variabel } & \multicolumn{2}{c}{ Rata-rata } & \multirow{2}{*}{ Kategori } \\
\cline { 2 - 3 } & Skor & $\%$ & \\
\hline Pemahaman Diri & 4 & 80,06 & Baik \\
$\begin{array}{l}\text { Pengetahuan Dunia } \\
\text { Kerja }\end{array}$ & 3,92 & 78,68 & Baik \\
$\begin{array}{l}\text { Pembuatan } \\
\text { Keputusan Tentatif }\end{array}$ & 3,63 & 72,71 & Baik \\
\hline \multicolumn{1}{c}{ Keseluruhan } & 3,84 & 76,81 & Baik \\
\hline
\end{tabular}

Berdasarkan data pada Tabel 3 secara keseluruhan skor rata-rata pada perencanaan karier siswa sebesar 3,84 $(76,81 \%)$ dan berada pada kategori baik. Dengan demikian, siswa memiliki perencanaan karier yang baik dalam menjalani tugas perkembangan kariernya. Hasil analisis korelasi antara persepsi siswa tentang program studi keahlian dengan perencanaan karier dipaparkan pada Tabel 4.

Tabel 4. Kaitan Persepsi Siswa tentang Program Studi Keahlian dengan Perencanaan Karier

Variabel N r-hitung Sig

\section{Persepsi Siswa tentang \\ Program Studi Keahlian \\ Perencanaan Karier \\ $260 \quad 0,801 \quad 0,000$}

Data pada Tabel 4 menunjukkan besarnya nilai koefisien korelasi antara variabel persepsi tentang program studi keahlian (X) dengan perencanaan karier (Y), yaitu 0,801 dengan signifikansi 0,000 yang lebih kecil dari 0,05. Hal tersebut membuktikan bahwa hipotesis yang menyatakan adanya hubungan positif antara persepsi siswa tentang program studi keahlian yang ditempati dengan perencanaan karier dapat diterima. 
Berdasarkan hasil penelitian yang dipaparkan sebelumnya maka dikemukakan pembahasan sebagai berikut.

\section{Persepsi Siswa tentang Program Studi Keahlian}

Hasil penelitian mengungkapkan pada umumnya persepsi siswa tentang program studi keahlian yang ditempati berada pada kategori positif. Artinya, siswa memiliki persepsi yang positif tentang program studi keahlian terkait dengan pembelajaran, kesesuaian program studi keahlian dengan diri siswa dan prospek program studi keahlian.

Hal tersebut menunjukkan siswa mampu menerima lingkungannya secara positif. Namun, masih ada beberapa siswa memiliki persepsi yang positif tentang program studi keahlian yang ditempati, tetapi berada di bawah rata-rata. Artinya, persepsi siswa sudah tergolong positif namun belum mencapai keadaan yang ideal.

Leavitt mengemukakan persepsi merupakan bagaimana seseorang memandang atau mengartikan sesuatu (Sobur, 2003). Dengan demikian, siswa memiliki pandangan atau penafsiran yang positif tentang program studi keahlian yang ditempatinya.

Bobbit dan Carters juga mengemukakan kurikulum pada suatu bidang studi memuat mata pelajaran yang harus diajarkan dan kegiatan belajar yang harus dilakukan untuk melatih dan mengembangkan kemampuan siswa (Ansyar, 2015). Artinya, siswa yang mampu mempersepsi dengan baik program studi keahlian yang ditekuni maka kemampuannya akan berkembang.

George Clark mengemukakan remaja lebih tertarik pada program studi keahlian yang mempelajari pelajaran yang nantinya akan berguna dalam bidang pekerjaan yang dipilih (Hurlock, 2002). Artinya, siswa yang menilai suatu program studi keahlian memiliki kaitan atau kegunaan terhadap pilihan pekerjaannya akan bersemangat menekuni program studi keahlian tersebut.

\section{Perencanaan Karier Siswa}

Berdasarkan hasil penelitian terungkap perencanaan karier siswa pada umumnya berada pada kategori baik. Artinya, siswa memiliki perencanaan karier yang baik dalam menjalani tugas perkembangan kariernya.

Hasil penelitian tersebut menunjukan siswa telah mampu merencanakan karier dengan baik. Ada beberapa siswa sudah memiliki perencanaan karier yang baik, tetapi berada di bawah rata-rata. Dengan demikian, ada siswa yang belum mencapai perkembangan karier yang optimal dalam hal merencanakan karier.

Perencanaan karier pada siswa merupakan kegiatan mempersiapkan diri dari kehidupan sekolah menuju dunia kerja agar mandiri dan berkembang secara optimal dengan cara memahami dirinya dan mempelajari dunia kerja untuk mendapatkan pengalaman dalam membuat keputusan dan mendapatkan pekerjaan (Salahudin, 2012).

Upaya menambah pengetahuan dunia kerja merupakan kegiatan individu untuk mengetahui dan memahami seluk-beluk dari berbagai macam jalur dalam memasuki karier yang ada. Faktor yang menentukan dalam memilih dan memasuki pekerjaan, yaitu (1) informasi pekerjaan, persyaratan yang bersifat teknis, ciri peranan sosial, urutan nilai-nilai yang menyenangkan, (2) aturan-aturan sosial psikis dan (3) perkembangan kepribadian (Gani, 1996). Indikasi dari perencanaan karier, yaitu pembuatan keputusan dengan mempertimbangkan keadaan diri dan lingkungan agar dapat melaksanakan kegiatan yang layak sesuai dengan peran dalam masyarakat (Aqib, 2012). Dengan demikian, siswa SMK sudah mulai membuat keputusan tentatif untuk melaksanakan kegiatan dalam mencapai perkembangan karier yang optimal.

\section{Persepsi Siswa tentang Program studi keahlian dan Kaitannya dengan Perencanaan karier}

Hasil penelitian membuktikan terdapat hubungan yang signifikan bernilai positif antara variabel persepsi tentang program studi keahlian dengan perencanaan karier. Artinya, semakin positif persepsi siswa tentang program studi keahlian yang ditempatinya maka semakin baik perencanaan kariernya.

Hasil temuan penelitian ini memperkuat teori yang dikemukakan oleh Myers Briggs bahwa individu mengobservasi dunia dengan melakukan persepsi tentang lingkungan sehingga timbul kesadaran individu tentang adanya kenyataan orang, objek atau ide dan penilaian tentang kenyataan yang ada tersebut. Setelah itu individu membuat keputusan karier berdasarkan penilaiannya (Sharf, 2010). Dengan demikian, penilaian dan penafsiran siswa tentang lingkungannya, yaitu program studi keahlian yang ditempatinya memiliki hubungan dengan perencanaan karier. 


\section{SIMPULAN DAN SARAN}

Berdasarkan penelitian yang dilakukan maka dapat disimpulkan: (1) Persepsi siswa tentang program studi keahlian yang ditempatinya secara umum berada pada kategori positif; (2) Perencanaan karier siswa secara umum berada pada kategori baik; (3) Terdapat hubungan antara persepsi siswa tentang program studi keahlian dengan perencanaan karier.

Berdasarkan hasil penelitian maka peneliti mengemukakan saran: (1) Pimpinan sekolah diharapkan menyelenggarakan kegiatan yang dapat mengembangkan kemampuan siswa untuk mencapai tugas perkembangan dalam merencanakan karier; (2) Guru BK diharapkan dapat menyusun dan menjalankan program bimbingan karier mengenai pemahaman siswa terhadap program studi keahlian, penyesuaian siswa dengan program studi keahliannya dan perencanan karier sehingga siswa siap dan mampu memilih karier yang sesuai dengan kemampuan dan kebutuhan masyarakat. Peneliti selanjutnya dapat menjadikan hasil penelitian ini sebagai bahan rujukan untuk meneliti permasalahan tentang persepsi dan perencanaan karier secara lebih luas berkaitan dengan faktor internal dan eksternal lainnya, seperti minat, budaya, sosial-ekomoni, dukungan sosial, konsep diri dan sebagainya.

\section{DAFTAR RUJUKAN}

Ansyar, M. 2015. Kurikulum: Hakikat, Pondasi, Desain dan Pengembangan. Jakarta: Prenadamedia Group.

Aqib, Z. 2012. Ikhtisar Bimbingan dan Konseling di Sekolah. Bandung: Yrama Widya.

Falentini, F. Y., Taufik, T., \& Mudjiran, M. (2013). Usaha yang dilakukan siswa dalam menentukan arah pilihan karir dan hambatan-hambatan yang ditemui. Konselor, 2(1).

Gani, R. A. 1996. Bimbingan Karir. Bandung: Angkasa.

Gladding, S. T. 2012. Konseling: Profesi yang Menyeluruh. Jakarta: Indeks.
Hurlock, E. B. 2002. Psikologi Perkembangan Suatu Pendekatan Sepanjang Rentang Kehidupan. Jakarta: Erlangga.

King, L. A. 2010. Psikologi Umum. Jakarta: Salemba Humanika.

Makmun, A. S. 2012. Psikologi Kependidikan. Bandung: Remaja Rosdakarya.

Prayitno \& Amti, E. 2004. Dasar-dasar Bimbingan dan Konseling. Jakarta: Rineka Cipta.

Salahudin, A. 2012. Bimbingan dan Konseling. Bandung: Pustaka Setia.

Sharf, R. S. 2010. Applying Career Development Theory to Counseling. USA: Brooks/Cole. Cengage Learning.

Sobur, A. 2003. Psikologi Umum. Bandung: Pustaka Setia.

Sumanto. 2014. Psikologi Umum. Yogyakarta: Center of Academic Publishing Service.

Supriatna, M., \& Budiman, N. (2010). Layanan Bimbingan Karier di Sekolah Menengah Kejuruan (e-book). Bandung: Departemen Pendidikan Nasional Universitas Pendidikan Indonesia.

Winkel, W. S. \& Hastuti, S. 2013. Bimbingan dan Konseling di Industri Pendidikan. Media Abadi: Yogyakartal 